\title{
Preparation and Reactions of Trifluoromethanesulfonic Arenesulfonic Anhydrides ${ }^{[1][* *]}$
}

By Franz Effenberger and Klaus Huthmacher ${ }^{{ }^{*}+}$

Dedicated to Professor Hellmut Bredereck on the occasion of his 70th birthday

In the course of our investigations on new electrophilic agents, we have reported on the preparation of trifluoromethanesulfonic carboxylic anhydrides and their high acylating potential ${ }^{[2]}$. We have now succeeded in obtaining the mixed sulfonic anhydrides ( 3 ) from sulfonyl bromides ( 1 ) and silver trifluoromethanesulfonate (2).

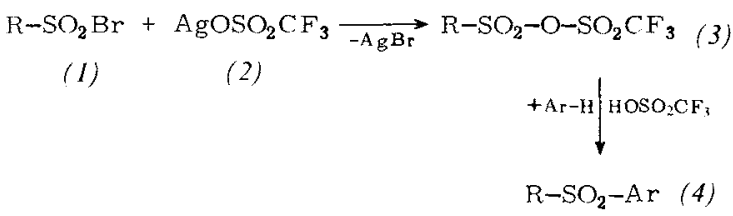

Since the anhydrides (3) are not stable in pure form, exact physical data cannot be given; their structure, however, is established unequivocally by ${ }^{1} \mathrm{H}-\mathrm{NMR}$ and by their reaction with arenes, yielding aryl sulfones (4) (Table 1).

The extraordinary sulfonylating potential of the anhydrides (3) is apparent from the reaction with an arene as unreactive as chlorobenzene, which is sulfonylated in high yield even at $0 \mathrm{C}$ (see Table 1). With sulfonyl halides, on the other hand, sulfones are formed from arenes only at elevated temperature and in the presence of Friedel-Crafts catalysts ${ }^{[3 \mid}$.

The anhydrides ( 3 ) are thermolabile; in the absence of arenes which can be sulfonylated they decompose in various ways depending on the nature of $\mathrm{R}$.

[*] Prof. Dr. F. Effenberger and Dipl-Chem. K. Huthmacher Institut für Organische Chemie der Universitia

7 Stuttgart 80. Pfaffenwaldring 55 (Germany)

[**] This work was supported by the Deutsche Forschungsgemeinschaft and the Fonds der Chemischen Industrie. 
For $\mathbf{R}=$ alkyl, heterolytic dissociation to (5) and subsequent loss of $\mathrm{SO}_{2}$ yielding (7) are observed; the decomposition temperature falls as the stabilization of the carbenium ion

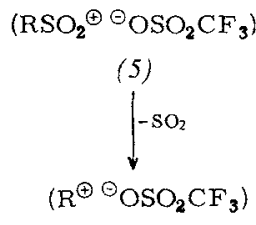

(7)

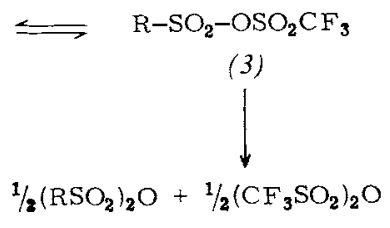

(8)

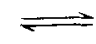

(9)

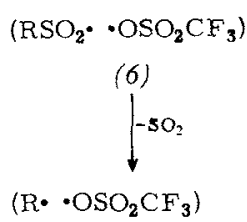

(10)

$\mathrm{R}^{\oplus}$ increases. Radicals (10) are formed preferentially from anhydrides with polyalkyl- and polyalkoxyarenesulfonic components, probably by homolysis to (6) and loss of $\mathrm{SO}_{2}$. The anhydrides listed in Table 1 suffer disproportionation into

Table 1. Preparation of trifluoromethanesulfonic arenesulfonic anhydrides (3) and their reaction with arenes to form sulfones (4) [a]

\begin{tabular}{|c|c|c|c|c|}
\hline \multicolumn{2}{|c|}{ Starting materials } & \multicolumn{3}{|c|}{ Products (4) } \\
\hline (1), R= & $\mathrm{Ar}-\mathrm{H}$ & sulfone & yield $[\%]$ & m.p. $[\because \mathrm{C}][\mathrm{b}]$ \\
\hline $4-\mathrm{NO}_{2}-\mathrm{C}_{6} \mathrm{H}_{4}-$ & benzene & 4-nitrodiphenyl & 34 & $142-143$ \\
\hline $4-\mathrm{Cl}-\mathrm{C}_{6} \mathrm{H}_{4}-$ & benzene & 4-chlorodiphenyl & 80 & 94 \\
\hline $\mathrm{C}_{6} \mathrm{H}_{5}-$ & benzene & diphenyl & 90 & 126 \\
\hline $4-\mathrm{CH}_{3}-\mathrm{C}_{6} \mathrm{H}_{4}-$ & benzene & 4-methyldiphenyl & 98 & $126-127$ \\
\hline $4-\mathrm{CH}_{3}-\mathrm{C}_{6} \mathrm{H}_{4}-$ & p-xylene & 2,5,4'-trimethyldiphenyl & 98 & 108 \\
\hline $4-\mathrm{CH}_{3}-\mathrm{C}_{6} \mathrm{H}_{4}-$ & toluene & di-p-tolyl $[\mathrm{c}]$ & 100 & \\
\hline $4-\mathrm{CH}_{3}-\mathrm{C}_{6} \mathrm{H}_{4}-$ & chlorobenzene & 4-chloro-4'-methyldiphenyl [d] & 80 & $123-124$ \\
\hline
\end{tabular}

[a] The anhydrides (3) were prepared from (1) and (2) at $0 . \mathrm{C}$ in nitromethane, and reacted with a threefold excess of arene $(\mathrm{Ar}-\mathrm{H})$ at the same temperature. The yields were determined by GLC. The yields obtained on a preparative scale are only slightly lower.

[b] The melting points of the sulfones (4) are in accordance with literature data. Mixed melting points with authentic material show no depression.

[c] Isomer distribution: $2,4^{\prime}: 3,4^{\prime}: 4,4^{\prime}=42: 5: 53$

[d] No other isomers could be detected.

(8) and (9) upon warming. Since this process already occurs at temperatures slightly above $50^{\circ} \mathrm{C}$, the anhydrides ( 3 ) cannot be prepared from (2) and the less reactive sulfonyl chlorides.

4-Methyldiphenyl sulfone, (4): $R=$ - p-tolyl, $A r=$ phenyl

Compound (2) $(2.56 \mathrm{~g}, 0.01 \mathrm{~mol})$ is dissolved in nitromethane $(10 \mathrm{ml})$ at $0{ }^{\circ} \mathrm{C}$, and a solution of $p$-toluenesulfonyl bromide $(2.35 \mathrm{~g}, 0.01 \mathrm{~mol})$ in nitromethane $(10 \mathrm{ml})$ is added. After $30 \mathrm{~min}$ stirring, benzene $(2.34 \mathrm{~g}, 0.03 \mathrm{~mol})$ is added. Stirring is continued for another $30 \mathrm{~min}$, chloroform $(20 \mathrm{ml})$ is added, the $\mathrm{AgBr}$ precipitate seperated, and the organic phase is washed with sodium carbonate solution and with water. The solvent is stripped off and the residue recrystallized from ethanol: yield $2.15 \mathrm{~g}(93 \%)$, m. p. $126-127^{\circ} \mathrm{C}\left(127-128^{\circ} \mathrm{C}^{[4]}\right)$; mixed m.p. $127^{\circ} \mathrm{C}$.

[1] Electrophilic Substitution of Aromatic Compounds, Part 9. - Part 8 F. Effenberger, H. Klenk, and P. L. Reiter, Angew. Chem. 85, 819 (1973) Angew. Chem. internat. Edit. 12,775 (1973).

[2] F. Effenberger and G. Epple, Angew. Chem. 84, 294 (1972); Angew. Chem. internat. Edit. 11, 300 (1972).

[3] F. R. Jensen and G. Goldman in G. A. Olah: Friedel-Crafts and Related Reactions. Wiley, New York 1964, Vol. 3, pp. $1319 \mathrm{ff}$, and further references cited therein.

[4] W. R. Gaythwaite, J. Kenyon, and H. Phillips, J. Chem. Soc, 192X, 2283. 